\title{
Chronic hepatitis B in Asian women of childbearing age
}

\author{
Nancy Leung
}

Received: 13 March 2009/Revised: 5 June 2009/Accepted: 17 June 2009/Published online: 9 July 2009

(C) Asian Pacific Association for the Study of the Liver 2009

\begin{abstract}
Hepatitis B virus (HBV) infection is a serious clinical problem affecting approximately 2 billion people worldwide. An estimated 350 million live with chronic hepatitis $\mathrm{B}(\mathrm{CHB})$ infection and are at an increased risk for serious liver sequelae and death from acute or chronic consequences of $\mathrm{CHB}$ infection. Individuals with $\mathrm{CHB}$ have a $20-30 \%$ risk of early death from complications, including liver cirrhosis and hepatocellular carcinoma. In the Asia-Pacific region, half of the CHB burden results from vertical or mother-to-child transmission, with early childhood horizontal transmission accounting for the remaining half. Screening and vaccination are key factors in the successful prevention and control of HBV infection. Over the last 20 years, the implementation of screening programs and universal HBV vaccination for all individuals born in endemic areas have reduced the prevalence of HBV infection and HBV-related liver diseases among individuals younger than 30 years. Women of childbearing age are key stakeholders in preventing HBV infection and, as such, play a critical role in reducing the vertical and horizontal transmission of HBV. Further efforts are needed to implement screening and educational programs for women of childbearing age, particularly those with CHB, to prevent the transmission of HBV to newborns, spouses, other household members, and sexual partners. In addition, healthcare workers need to learn how to avoid iatrogenic transmission in the healthcare setting. This article reviews
\end{abstract}

N. Leung $(\square)$

Department of Medicine, Alice Ho Miu Ling Nethersole

Hospital, Chinese University of Hong Kong, Room 65, J6, 11

Chuen On Road, Tai Po, NT, Hong Kong SAR, China

e-mail: leungwyn@ha.org.hk; nancyleung@cuhk.edu.hk these issues and highlights areas in which their engagement with public health efforts serves to improve quality of life and society as a whole.

Keywords Chronic hepatitis B - Women of childbearing age $\cdot$ Hepatitis B virus · Pregnancy

\section{Introduction}

Hepatitis B virus (HBV) infection remains a serious clinical problem because of its worldwide distribution and potential, adverse liver-related sequelae. HBV and chronic hepatitis B (CHB) are endemic in the Asia-Pacific region, where they are leading causes of serious liver morbidity and mortality. The prevalence of HBV serologic markers indicates the HBV infection status in the specific populations studied. Hepatitis B surface antigen (HBsAg) is a serologic marker of infection and can be detected during chronic and acute hepatitis B infection; antibody to hepatitis B surface antigen (anti-HBs) is a marker of immunity from exposure to HBV or HBV vaccine; and immunoglobulin $\mathrm{G}(\mathrm{IgG})$ antibody to core hepatitis B antigen (anti$\mathrm{HBc}$ ) is a marker of exposure to $\mathrm{HBV}$ and is detectable in individuals with acute hepatitis $\mathrm{B}, \mathrm{CHB}$, or past $\mathrm{HBV}$ infection. Generally speaking, HBsAg seroprevalence usually reflects the presence of $\mathrm{CHB}$ in a given population. The rate of HBV infection is estimated to be $36-57 \%$ and HBsAg prevalence ranges from 3.8 to $16.8 \%$ in Mainland China, with higher rates observed in rural areas [1]. The seroprevalence of HBsAg among adults in other Asian countries has remained similar over the past two decades, ranging from 2 to 20\% [2-13]. CHB runs an insidious and often progressive course and, when left untreated, can lead to cirrhosis, decompensated liver disease, and 
hepatocellular carcinoma (HCC) [14]. The associated morbidity, mortality, and medical health expenditure are immense. Complications usually start to manifest in adulthood, often in the prime of an individual's life, and often result in much personal and social distress.

Most Asians with CHB are infected at birth or in early infancy by CHB-infected mothers $[15,16]$. The risk of intrauterine infection is relatively low because the fetus is protected from HBV by the placenta. Horizontal transmission from fathers, siblings, and playmates with CHB is a significant factor. Early infant infection seldom manifests as symptomatic acute hepatitis but evolves to chronic infection. Evidence from long-term follow-up studies on the impact of the implementation of universal HBV vaccination programs in Taiwan has clearly demonstrated that the prevention of mother-to-child transmission is the mainstay for the control of HBV infection in the AsiaPacific region [17-20].

CHB seldom causes specific symptoms. Serostatus can be established only by blood tests for HBsAg, infectivity can be established by blood tests for HBV DNA, and the presence of disease can be established by regular monitoring with blood tests and liver imaging. Without therapeutic intervention, at least $30 \%$ of individuals with CHB will develop significant disease [21]. The interaction of the host immune system and the virus determines the outcome and the natural course of disease, which consists of 3 phases: the immune-tolerant, immune clearance, and inactive residual phases [22]. The immune-tolerant phase, when the host immune system does not react to active viral replication, is characterized by the presence of hepatitis $\mathrm{B}$ e antigen ( $\mathrm{HBe} \mathrm{Ag}$ ), high serum HBV DNA levels (at least $2 \times 10^{9}$ copies $/ \mathrm{ml}$ ), normal alanine aminotransferase (ALT) levels, and an absence of hepatitis activity. After a variable duration, the individual enters the immune clearance phase, when host immune reaction to $\mathrm{HBV}$ is characterized by a reduction in serum HBV DNA levels, intermittent acute ALT flares that can exceed 5 times the upper limit of normal (ULN), and evidence of active hepatitis upon liver biopsy. The loss of HBeAg and the appearance of antibody to hepatitis $\mathrm{B}$ e antigen (anti$\mathrm{HBe}$ ), referred to as $\mathrm{HBeAg}$ seroconversion, mark the transition to the inactive residual phase, which is followed by a reduction in serum HBV DNA levels, sometimes beyond the limit of detectability, and the clinical remission of liver disease. Women with CHB generally have a better prognosis and go through the first two phases of the disease (i.e., the immune-tolerance and immune clearance phases) to the third, inactive, phase. However, some will progress to $\mathrm{HBeAg}$-negative $\mathrm{CHB}$ [23, 24]. Individuals with active viral replication are capable of transmitting the infection. Most individuals with $\mathrm{CHB}$ remain $\mathrm{HBsAg}$ positive throughout their lives due to the persistence of very low-grade $\mathrm{HBV}$ infection. Only a small percentage $(\sim 0.5 \%)$ of patients with $\mathrm{CHB}$ may lose HBsAg and even undergo HBsAg seroconversion.

\section{Prevalence of CHB among Asian women of childbearing age}

Data from the World Health Organization (WHO), the United Nations Children's Fund (UNICEF), the Red Cross Blood Donation Service, local healthcare agencies, and independent research groups that monitor the epidemiology of HBV infection in Asian countries have shown a trend toward decreasing infection in the majority of these countries. The seroprevalence of HBsAg is generally lower in women than in men. Before the introduction of the HBV vaccine during the 1980s, the male-to-female ratio was 1.4:1 in China, 1.3:1 in Thailand, and 1.1:1 in Hong Kong. One-third of the 3 million individuals infected annually come from China. A national seroepidemiologic survey in 2002 showed that $10-12 \%$ of the adult population and $5 \%$ of children younger than 5 years were HBsAg positive. Taiwan also has a high rate of HBsAg seroprevalence (10-14\%) among its adult population, whereas prevalence rates in the Philippines are $2-16.5 \%$, Vietnam and Thailand $14 \%$, and Southeast Asia, Japan, Korea, and India at a more modest 2-5\% $[2,3,6,7,9,11,13]$. In many developing countries, HBsAg seroprevalence also differs between urban and rural areas. In Vietnam, seroprevalence is as high as $20 \%$ in the rural Thanh Ho province, but only $10 \%$ in Ho Chi Minh City. In China, on the other hand, HBsAg prevalence is $10.1 \%$ in rural areas and $8.8 \%$ in urban areas. HBsAg seroprevalence varies among different ethnic groups. It has been reported to be $13.8 \%$ among the Hmong and Lahu tribes compared with $22.6 \%$ among the general population in northern Thailand. Similarly, HBsAg seroprevalence was $17 \%$ among the aboriginal Fukien and Hakka populations in Taiwan compared with a prevalence of $26 \%$ among the general population [4, 5 , $8,10,12]$. The reason for these differences may be related to the high endemicity carried down from one generation to the next by vertical transmission as well as horizontal transmission.

Epidemiologic reviews indicate that Asian patients generally undergo $\mathrm{HBeAg}$ seroconversion at a median age of 35 years. Viral clearance occurs at an estimated annual incidence of $2-15 \%[25,26]$. In a cross-sectional analysis of 544 women, aged $18-50$ years, with $\mathrm{CHB}$, who were followed in a district hospital in Hong Kong, 38.4\% were $\mathrm{HBeAg}$ positive and $61.6 \%$ were $\mathrm{HBeAg}$ negative [27]. In the younger cohort (18-30 years of age), the HBeAg positivity rate was higher at $50.3 \%$. Serum HBV DNA levels 
were more than $8 \log _{10}$ copies $/ \mathrm{ml}$ in $55.6 \%$ of the patients; none had HBV DNA levels less than $2 \log _{10}$ copies $/ \mathrm{ml}$. Among patients aged $31-40$ years, the $\mathrm{HBeAg}$ positivity rate was $34.9 \%$, with $53.8 \%$ of patients having HBV DNA levels of more than $8 \log _{10}$ copies $/ \mathrm{ml}$. This demonstrates the higher risk of vertical and horizontal mother-to-child transmission in younger mothers [27]. These data can help facilitate a healthcare strategy, but the severity of liver disease in these women needs to be assessed on an individual basis.

\section{CHB in women and its effect on pregnancy}

Women with $\mathrm{CHB}$ generally undergo earlier $\mathrm{HBeAg}$ seroconversion and enter the quiescent phase sooner than do their male counterparts. Some women may have progressed to the phase of inactive disease or phase of HBeAg-negative active CHB [28]. This observation has stimulated much research interest in the role and influence of sex hormones on the host immune interaction with HBV. Hormonal changes during pregnancy enhance the immune clearance of HBV [29, 30].

A Swedish retrospective study showed that serum HBV DNA levels increased by a mean of $0.4 \log _{10}$ copies $/ \mathrm{ml} \mathrm{late}$ in pregnancy and during the early postpartum period. Even in HBeAg-negative mothers, serum HBV DNA levels increased in $25 \%$ of the patients by more than $1 \log _{10}$ copies/ml during pregnancy. Elevations in ALT levels occurred in both $\mathrm{HBeAg}$-positive and HBeAg-negative women in late pregnancy and immediately postpartum [31, 32]. The incidence of fulminant hepatitis is increased in pregnant women with $\mathrm{CHB}$, especially in the last trimester, compared with nonpregnant women and men with CHB. In a review of 35 mothers with CHB in Singapore, $75 \%$ were unaware that they were infected [33]. In these patients, HBsAg-positive status was documented for the first time at an antenatal registry when they were in their second trimester. Of this group, $66 \%$ were $\mathrm{HBeAg}$ positive and just over 50\% had elevated ALT levels. Loss of HBeAg during pregnancy was significantly higher in these patients than in controls $(P=0.002)$. No hepatic decompensation was recorded in this cohort.

Some women of childbearing age may have advanced disease that reduces fertility. The risk of complications during vaginal delivery in patients with cirrhosis and portal hypertension can be reduced by elective cesarean delivery. A telephone interview survey by the Chinese University of Hong Kong showed that many women were worried about their infection adversely affecting their health and damaging their offspring. Many decided not to get pregnant because of erroneous information.

\section{Antiviral treatment options for CHB in women of childbearing age and during pregnancy}

Clinical experience is limited with regard to the management of CHB in women of childbearing age and during pregnancy. Currently, there is no gold standard for CHB treatment in this population. Recently, treatment guidelines for CHB published by the Asian Pacific Association for the Study of the Liver recommended interferon (IFN)-based therapy for the treatment of nonpregnant women of childbearing age who have CHB [34]. However, IFN-based therapy is contraindicated in women who are pregnant or plan to become pregnant because of its antiproliferative/ teratogenic effect. Oral nucleos(t)ide analogs (NAs) may be considered for therapy, but among these agents only telbivudine and tenofovir are classified as category B drugs (i.e., demonstrating no risk in animal studies, but of unknown risk in humans), whereas lamivudine, adefovir, and entecavir are classified as category $\mathrm{C}$ drugs (i.e., teratogenic in animal studies, but of unknown risk in humans) by the US Food and Drug Administration [35]. Tenofovir treatment during pregnancy in women infected with the human immunodeficiency virus (HIV) is associated with a low rate of birth detects, particularly when it is given in the second and third trimesters (Table 1). Before selecting treatment, it is important to consider the stage of the mother's liver disease and potential benefit of treatment in relation to the potential risk to the fetus. Women of childbearing age should consider delaying pregnancy and receiving pegylated IFN (PEG-IFN) therapy first, especially if their serum ALT levels are 2-5 times the ULN. If their ALT level is less than 2 times the ULN and/or they have compensated cirrhosis, they should consider pregnancy first and begin treatment after the infant is born. This strategy is feasible in most families that plan for 1 or 2 offspring but may be difficult if a large family is planned. The physician must have an open and detailed discussion to help the women and their families reach the best decision. For women who become pregnant while receiving oral NA therapy, current guidelines recommend continuing treatment if the drug is a category B drug such as telbivudine and tenofovir [34]. Emerging evidence suggests that the use of lamivudine in the last month of pregnancy might prevent mother-to-infant transmission of $\mathrm{HBV}$ in women with high HBV DNA levels [36-40].

One recent study assessed the effect of lamivudine therapy during pregnancy in 150 highly viremic pregnant women who were randomized to receive lamivudine $100 \mathrm{mg}$ or placebo, from week 32 of gestation to week 4 postpartum [36]. After birth, infants from lamivudinetreated mothers were treated immunoprophylactically with lamivudine, $\mathrm{HBV}$ vaccine, and hepatitis B immunoglobulin (HBIG) $(n=56)$ or lamivudine and HBV vaccine 
Table 1 Birth defect rate by trimester of earliest exposure: comparison of exposure to tenofovir regimen and exposure to all antiretrovirus regimen in patients with HIV infection

\begin{tabular}{llll}
\hline Trimester & Parameter & Tenofovir regimen & All antiretroviral regimen \\
\hline First & Defects/live births & $14 / 606$ & $126 / 4,326$ \\
& Prevalence (95\% CI) & $2.3 \%(1.3-3.9)$ & $2.9 \%(2.4-3.5)$ \\
Second/third & Defects/live births & $5 / 336$ & $145 / 5,618$ \\
& Prevalence (95\% CI) & $1.5 \%(0.5-3.4)$ & $2.6 \%(2.2-3.0)$ \\
\hline
\end{tabular}

CI confidence interval

$(n=26)$, whereas infants from placebo-treated mothers received placebo, HBV vaccine, and $\mathrm{HBIG}(n=59)$. There were no maternal or fetal safety issues observed in any of the treatment arms. Efficacy results showed that lamivudine reduced $\mathrm{HBV}$ transmission from mothers to infants who received passive-active immunization, as measured by a decrease in the incidence of HBsAg seropositivity and in detectable HBV DNA levels. Although the results from this study are positive, questions have been raised regarding the extent of benefit, the maternal threshold serum HBV DNA level required for initiating therapy, the optimal initiation and duration of therapy, and the appropriate choice of therapy [41].

\section{Women's role in the prevention of HBV transmission}

\section{Prevention of mother-to-child transmission}

The prevention of vertical transmission from CHB-infected mothers to their children reduces HBV-related mortality in the long run. This can be achieved by the universal vaccination of newborns in endemic areas. Plasma-derived vaccines used in the 1980s were effective, but there were unsubstantiated concerns of transmission of HIV infection. Recombinant vaccines were then introduced; these were safe, effective, and affordable. The implementation of mass immunization programs recommended by the WHO since 1991 has decreased the incidence of HBV infection among infants, children, and adolescents in many countries. The advances in the prevention of $\mathrm{HBV}$ transmission have yielded encouraging results. Taiwan introduced an HBV vaccination program in 1988, and HBIG was additionally given to infants of $\mathrm{HBeAg}$-positive mothers [20, 42, 43]. In 2004, a survey showed seropositive rates for HBsAg, anti$\mathrm{HBs}$, and anti-HBc of $1.2,50.5$, and $3.7 \%$, respectively, in individuals born since the introduction of the vaccination program (i.e., individuals younger than 20 years). Individuals positive for $\mathrm{HBsAg}$ were born mostly to $\mathrm{HBsAg}$ positive mothers. In the actively followed cohort, no increased incidence of $\mathrm{CHB}$ was found. Vaccination reduces both vertical and horizontal transmission.
The incidence of liver cancer among children has also been reduced significantly. In a long-term study involving 318 children in Hong Kong, which sought to evaluate the immunogenicity and efficacy of different regimens of HBV vaccination, no patients were found to be $\mathrm{HBsAg}$ positive during the 22 years of follow-up and 72 of 317 patients had at least 1 episode of amnesic response (i.e., rapid and more pronounced production of anti-HBs upon second encounter with HBsAg antigen) [44].

However, many endemic countries have not been able to provide good coverage to their citizens. Recombinant HBV vaccines are still relatively expensive, and there are no efficient and dedicated healthcare systems to deliver the important first dose to infants within $24 \mathrm{~h}$ of birth. Lack of knowledge among mothers, compounded by a lack of commitment from the healthcare providers, creates major barriers to improvement. In response to this, the Global Alliance for Vaccines and Immunization plan was established by the WHO. This has dramatically increased access to vaccines in poor countries, such as Cambodia, China, the Lao People's Democratic Republic, and Vietnam. In 2002, the WHO Working Group met in Tokyo and reiterated its immunization strategies. These include plans to ensure quality of routine immunization services, especially coverage, injection safety, universal infant immunization with a high-risk approach that focuses on protecting the infants of HBV-infected mothers, timely delivery of a birth dose (within $24 \mathrm{~h}$ of birth), and the addition of vaccine vial monitors in remote areas facilitated by UNICEF-procured vaccines. As part of the expanded program on immunization developed by the WHO in conjunction with UNICEF and a coalition of partners, the regional milestones used to monitor the progress of HBV control included at least $80 \%$ full immunization (receipt of three doses of HBV vaccine), a system to monitor the timeliness of birth doses by 2004, the achievement of HBsAg seroprevalence of less than $1 \%$ in individuals born after routine vaccination started, and the establishment of a hepatitis B control plan that includes a protocol to monitor healthcare worker knowledge. Currently, all countries in the Asia-Pacific region except the Philippines, India, and Cambodia have implemented universal infant immunization programs. Data from UNICEF 
from 2005 indicated that $\mathrm{HBV}$ vaccine coverage in infants ranged from 70 to $90 \%$ in most Asia-Pacific countries [45]. Unfortunately, the implementation of vaccination programs is reportedly inconsistent and access to these programs remains limited in some countries such as Myanmar, Bangladesh, and India as well as some rural areas, such as remote areas of China, where coverage is only $29 \%[2,6$, 13, 45, 46] (Table 2). Vaccine failure leading to vertical transmission remains a challenge. This may be reduced by administering HBIG to infants whose mothers are $\mathrm{HBeAg}$ positive or have high serum levels of HBV DNA.

A review of the response to HBV vaccination among newborns has shown that $7-10 \%$ of nonresponders or insufficient responders have anti-HBs levels of less than $10 \mathrm{IU} / 1$. A number of possibilities account for poor response to HBV vaccination. These include intrauterine infection, vaccine escape mutants, host genetic hyporesponsiveness or nonresponsiveness to $\mathrm{HBsAg}$, and immune compromise.

The proposal to use oral antiviral agents to reduce maternal HBV DNA serum levels in the third trimester and immediate postnatal period to avoid mother-tonewborn transmission was evaluated in a pilot study using antiviral therapy, such as lamivudine, in the third trimester to reduce maternal serum HBV DNA level by the time of birth [37]. However, the trial did not yield convincing efficacy results. One $(12.5 \%)$ of the eight offspring of highly viremic mothers receiving lamivudine $150 \mathrm{mg}$ still became infected and had CHB, compared with $28 \%$ of historic controls who did not receive lamivudine therapy. Thus, the administration of oral antiviral therapy in the third trimester to women with $\mathrm{CHB}$ is controversial because there is no evidence to confirm a significant reduction in infection rates among infants and, more important, the safety of antiviral therapy in pregnant women is unproven. Withdrawal flare after delivery is an additional safety concern [37]. Antiviral therapy may not be available for mothers with CHB in developing regions where there is no healthcare system to oversee the administration of complicated management regimens.

Mathematical models have been used to project disease trends and the impact of HBV vaccination on disease outcome. In Vietnam, the prevalence of CHB among men and women was estimated on the basis of age-specific HBV prevalence from Vietnamese community-based studies. Universal infant $\mathrm{HBV}$ vaccination from 2003 was assumed to reduce HBV infection by $90 \%$ in subsequent birth cohorts. Over the next two decades, universal infant HBV vaccination is expected to reduce chronic HBV prevalence in Vietnam, from 8.4 million cases in 2005 to 8.0 million cases by 2025 . However, the HBV-related liver disease burden from cirrhosis and HCC will continue to rise on the basis of the estimated incidence with HBV DNA levels from the Taiwanese Risk Evaluation of Viral Load Elevation and Associated Liver Disease/Cancer in HBV (REVEAL-HBV) study [47, 48]. Estimated HBV-related mortality is expected to increase from 12,600 in 1990 to

Table 2 Demographic and health statistics for children living in the Asia-Pacific region in 2006

\begin{tabular}{|c|c|c|c|c|c|c|c|c|c|}
\hline Country & $\begin{array}{l}\text { Life } \\
\text { expectancy } \\
\text { (year) }\end{array}$ & $\begin{array}{l}\text { Urbanized } \\
\text { population } \\
\text { in } 2006(\%)\end{array}$ & $\begin{array}{l}\text { Contraceptive } \\
\text { users }(\%)\end{array}$ & $\begin{array}{l}\text { Antenatal } \\
\text { care } \\
\text { coverage } \\
(\%)\end{array}$ & $\begin{array}{l}\text { Skilled } \\
\text { attendant at } \\
\text { delivery } \\
(\%)\end{array}$ & $\begin{array}{l}\text { Institutional } \\
\text { deliveries } \\
(\%)\end{array}$ & $\begin{array}{l}\text { Lifetime risk } \\
\text { of maternal } \\
\text { death }(1 \text { in } \ldots)\end{array}$ & $\begin{array}{l}\text { One-year- } \\
\text { olds immune } \\
\text { to HBV }(\%)\end{array}$ & $\begin{array}{l}\text { Mothers } \\
\text { not breast- } \\
\text { feeding } \\
(\%)\end{array}$ \\
\hline Bangladesh & 63 & 25 & 58 & 48 & 20 & 16 & 51 & 88 & 37 \\
\hline Cambodia & 59 & 20 & 40 & 69 & 44 & 22 & 48 & 80 & 60 \\
\hline China & 73 & 41 & 87 & 90 & 98 & 83 & 1,300 & 91 & 51 \\
\hline India & 64 & 29 & 56 & 74 & 47 & 41 & 300 & 6 & 6 \\
\hline Indonesia & 70 & 49 & 57 & 92 & 72 & 40 & 97 & 70 & 40 \\
\hline Japan & 82 & 66 & 56 & NA & 100 & NA & 11,600 & NA & NA \\
\hline Korea & $67 / 78$ & $62 / 81$ & $62 / 81$ & NA/NA & $97 / 100$ & NA/NA & $140 / 6,100$ & $96 / 99$ & 65 \\
\hline $\begin{array}{l}\text { Lao People's } \\
\text { Democratic } \\
\text { Republic }\end{array}$ & 64 & 21 & 32 & 27 & 19 & NA & 33 & 57 & 57 \\
\hline Malaysia & 74 & 68 & 55 & 79 & 98 & 98 & 560 & 87 & 87 \\
\hline Myanmar & 61 & 31 & 34 & 76 & 57 & 16 & 110 & 75 & 75 \\
\hline Pakistan & 65 & 35 & 28 & 36 & 31 & 28 & 74 & 83 & 83 \\
\hline Philippines & 71 & 63 & 49 & 88 & 60 & 38 & 140 & 27 & 88 \\
\hline Thailand & 70 & 33 & 77 & 98 & 92 & 97 & 500 & 96 & 96 \\
\hline Vietnam & 74 & 27 & 76 & 91 & 88 & 64 & 280 & 93 & 93 \\
\hline
\end{tabular}

Reprinted with permission from UNICEF [45] 
40,000 in 2025 [49]. A national HBV strategy is required to address this expanding burden of liver disease.

\section{Prevention of horizontal transmission of HBV}

HBV can be transmitted through sexual intercourse, close social contact, and parenteral exposure. CHB-infected women of childbearing age may transmit $\mathrm{HBV}$ infection to their sexual partners, other household members, and occupational contacts, especially if they work in the healthcare setting. Unfortunately, health knowledge and hygiene tend to be low in many parts of the Asia-Pacific region, and health policy in general does not address these issues thoroughly. Many CHB-infected individuals are not aware of their HBV status and transmit the infection unknowingly.

Sexual transmission may not add to the chronicity burden but can result in acute hepatitis B. Women with CHB may infect their nonimmunized partners if safe sex is not practiced. Professional sex workers are at risk of acquiring and transmitting HBV and other sexually transmitted diseases [50].

Immigration from the East to the West introduces Asian populations with a higher prevalence of CHB to areas in which most individuals are not immune to hepatitis B. This has the potential to increase the incidence of acute hepatitis B [51, 52]. Recently, the Centers for Disease Control and Prevention (CDC) published updated and expanded guidelines for HBsAg testing and new recommendations for public health evaluation and management for persons with chronic infection and their contacts [53]. Routine testing for HBsAg now is recommended for additional populations with an HBsAg prevalence of $2 \%$ or more: persons born in geographic regions with an HBsAg prevalence of $2 \%$ or more, men who have sex with men, and injection drug users [53]. The CDC guidelines serve as a resource on the management of HBV infection for public health officials, organizations, and healthcare professionals involved in the development, delivery, and evaluation of the prevention of HBV.

In many Asian countries, women constitute the majority of the healthcare workforce. As a result, there are woman physicians and surgeons, nurses, and healthcare assistants who suffer from CHB. The occupational risk of healthcare workers transmitting HBV infection to their patients has been well documented in the past. Health authorities in the United States, Canada, and the European Union have issued guidelines for healthcare workers who have CHB to prevent infecting patients through open wounds, medical interventions, or surgery. Different guidelines exist for the management of HBV-infected healthcare workers. Various HBV DNA levels are used as cutoff points to determine whether an HBV-infected healthcare worker will be allowed to perform exposure-prone procedures (EPPs). If the level of HBV DNA in the serum is used to determine acceptability for the conduct of EPPs, it is necessary to take into account the variability of HBV DNA levels over time in HBV carriers and the reliability and reproducibility of the molecular diagnostic test involved. The issue of standardization has to be addressed before a universal, maximum level of viremia for healthcare workers performing EPPs can be introduced [54]. Currently, there are no strict guidelines in Asian countries to prevent CHB-infected female healthcare workers from being employed in fields that involve patient contact and open-wound care. The prevention of transmission relies on universal precautions.

\section{Conclusion}

CHB is still endemic in many countries in the Asia-Pacific region, and the healthcare burden will continue to rise. Looking ahead, the healthcare costs for CHB-related disease should decline over time because serious complications are now avoidable with effective therapy. In addition, the impact of universal vaccination programs for HBV should alleviate the vicious cycle of vertical transmission and high chance of chronicity. The success of these strategies requires the dedication of local and national health authorities to provide appropriate resources and vaccines. Better health education for women of childbearing age will also help ensure better antenatal care.

Acknowledgment Editorial support in the development of the manuscript was provided by Kathleen Covino, $\mathrm{PhD}$. This study has been supported by an independent educational grant from BristolMyers Squibb Company through the ACT-HBV Initiative.

\section{References}

1. Zhao K. Epidemiology of hepatitis B in China. In Lam SK, Lai CL, Yeok EK, editors. Viral Hepatitis B Infection in the Western Pacific Region: Vaccine and Control. Singapore: World Scientific; 1984. 23-28

2. Centers for Disease Control and Prevention. Progress in hepatitis B prevention through universal infant vaccination-China, 19972006. MMWR Morb Mortal Wkly Rep 2007;56:441-445

3. Ebright JR, Altantsetseg T, Oyungerel R. Emerging infectious diseases in Mongolia. Emerg Infect Dis 2003;9:1509-1515

4. Edstam JS, Dulmaa N, Nymadawa P, Rinchin A, Khulan J, Kimball AM. Comparison of hepatitis B vaccine coverage and effectiveness among urban and rural Mongolian 2-year-olds. Prev Med 2002;34:207-214

5. Hipgrave DB, Nguyen TV, Vu MH, Hoang TL, Do TD, Tran NT, et al. Hepatitis B infection in rural Vietnam and the implications for a national program of infant immunization. Am J Trop Med Hyg 2003;69:288-294

6. Lavanchy D. Hepatitis B virus epidemiology, disease burden, treatment, and current and emerging prevention and control measures. J Viral Hepat 2004;11:97-107 
7. Lin HH, Kao JH, Chang TC, Hsu HY, Chen DS. Secular trend of age-specific prevalence of hepatitis B surface and e antigenemia in pregnant women in Taiwan. J Med Virol 2003;69:466-470

8. Louisirirotchanakul S, Myint KS, Srimee B, Kanoksinsombat C, Khamboonruang C, Kunstadter $\mathrm{P}$, et al. The prevalence of viral hepatitis among the Hmong people of northern Thailand. Southeast Asian J Trop Med Public Health 2002;33:837-844

9. Merican I, Guan R, Amarapuka D, Alexander MJ, Chutaputti A, Chien RN, et al. Chronic hepatitis B virus infection in Asian countries. J Gastroenterol Hepatol 2000;15:1356-1361

10. Qu JB, Zhang ZW, Shimbo S, Watanabe T, Nakatsuka H, Matsuda-Inoguchi $\mathrm{N}$, et al. Urban-rural comparison of HBV and $\mathrm{HCV}$ infection prevalence in eastern China. Biomed Environ Sci 2000; $13: 243-253$

11. Tran HT, Ushijima H, Quang VX, Phuong N, Li TC, Hayashi S, et al. Prevalence of hepatitis virus types B through E and genotypic distribution of $\mathrm{HBV}$ and $\mathrm{HCV}$ in Ho Chi Minh City. Vietnam Hepatol Res 2003;26:275-280

12. Wiwanitkit V, Suyaphan A. High prevalence of HBsAg seropositivity in Hilltribers in the Mae Jam district in northern Thailand. Med Gen Med 2002;4:26

13. World Health Organization Regional Office for Western Pacific. REPORT on Working Group Meeting on Viral Hepatitis B. Manilla, Philippines: World Health Organization Regional Office for Western Pacific; July 2002. (WP)/ICP/EPI/5.2/001-A. Report Series No.: RS/2002/GE/05 (Japan)

14. Fattovich G, Bortolotti F, Donato F. Natural history of chronic hepatitis B: special emphasis on disease progression and prognostic factors. J Hepatol 2008;48:335-352

15. Lee AKY, Ip H, Wong VCW. Mechanisms of maternal-fetal transmission of hepatitis B virus. J Infect Dis 1978;138:668-671

16. Stevens CE, Beasley RP, Tsui J, Lee WC. Vertical transmission of hepatitis B antigen in Taiwan. N Engl J Med 1975;292: 771-774

17. Chang MH, Chen CJ, Lai MS, Hsu HM, Wu TC, Kong MS, et al. Universal hepatitis B vaccination in Taiwan and the incidence of hepatocellular carcinoma in children. N Eng J Med 1997;336: 1855-1859

18. Chen DS. Hepatocellular carcinoma in Taiwan. Hepatol Res 2007;37(Suppl 2):S101-S105

19. Chien YC, Jan CF, Kuo HS, Chen CJ. Nationwide hepatitis vaccination program in Taiwan: effectiveness in the 20 years after it was launched. Epidemiol Rev 2006;28:126-135

20. Ni YH, Huang LM, Chang MH, Yen CJ, Lu CY, You SL, et al. Two decades of universal hepatitis $\mathrm{B}$ vaccination in Taiwan: impact and implication for future strategies. Gastroenterology 2007;132:1287-1294

21. Lau GKK, Carman C, Locarnini SA, Okuda K, Lu Z-M, William $\mathrm{R}$, et al. Treatment of chronic hepatitis B virus infection: an AsiaPacific perspective. J Gastroenterol Hepatol 1999;14:3-12

22. Liaw YF, Chu CM. Hepatitis B virus infection. Lancet 2009;373: $582-592$

23. Fung J, Lai CL, But D, Wong D, Cheung TK, Yuen MF. Prevalence of fibrosis and cirrhosis in chronic hepatitis B: implications for treatment and management. Am J Gastroenterol 2008;103: 1421-1426

24. Liaw YF, Chu CM, Lin DY, Sheen IS, Yang CY, Huang MJ. Age-specific prevalence and significance of hepatitis B e antigen and antibody in chronic hepatitis B virus infection in Taiwan: a comparison among asymptomatic carriers, chronic hepatitis, liver cirrhosis, and hepatocellular carcinoma. J Med Virol 1984;13: 385-391

25. Wang Z, Zhang J, Yang H, Li X, Wen S, Guo Y, et al. Quantitative analysis of HBV DNA level and $\mathrm{HBeAg}$ titer in hepatitis B surface antigen positive mothers and their babies: $\mathrm{HBeAg}$ passage through the placenta and the rate of decay in babies. $\mathrm{J}$ Med Virol 1993;71:360-366

26. Yuen MF, Yuan HJ, Hui CK, Wong DK, Wong WM, Chan AO, et al. A large population study of spontaneous $\mathrm{HBeAg}$ seroconversion and acute exacerbation of chronic hepatitis B infection: implications for antiviral therapy. Gut 2003;52:416-419

27. Leung N, Yeung C, Chan R, et al. Features of chronic hepatitis B female patients of childbearing age in Hong Kong. Hepatol Int; 2009 , in press

28. Lok ASF. Chronic hepatitis B: perspective. N Engl J Med 2002; 346:1682-1683

29. Carr BR, Parker CR Jr, Madden JD, MacDonald PC, Porter JC. Maternal plasma adenocorticotropin and cortisol relationships throughout human pregnancy. Am J Obstet Gynecol 1981;139: 416-422

30. Hidaka Y, Amino N, Iwatani Y, Kaneda T, Mitsuda N, Morimoto $\mathrm{Y}$, et al. Changes in natural killer cell activity in normal pregnant and post-partum women increases in the first and second postpartum period and decrease in late pregnancy. J Reprod Immunol 1991;20:73-83

31. Lin HH, Chen PJ, Chen DS, Sung JL, Yang KH, Young YC, et al. Post-partum subsidence of hepatitis B viral replication in $\mathrm{HBeAg}$ positive carrier mothers. J Med Virol 1989;29:1-6

32. Söderström A, Norkrans G, Lindh M. Hepatitis B virus DNA during pregnancy and post partum: aspects on vertical transmission. Scand J Infect Dis 2003;35:814-819

33. Tan HH, Lui H-F, Chow W-C. Chronic hepatitis B virus (HBV) infection in pregnancy. Hepatol Int 2008;3:370-375

34. Liaw Y-F, Leung N, Kao J-H, Piratvisuth T, Gane E, Han K-H, et al. Asian-Pacific consensus statement on the management of chronic hepatitis B: a 2008 update. Hepatol Int 2008;2:263-283

35. Hoofnagle JH, Doo E, Liang TJ, Fleischer R, Lok AS. Management of hepatitis B: summary of a clinical research workshop. Hepatology 2007;45:1056-1075

36. Xu WM, Cui YT, Wang L, Yang H, Liang ZQ, Li XM, et al. Lamivudine in late pregnancy to prevent perinatal transmission of hepatitis B virus infection: a multicentre, randomized, doubleblind, placebo-controlled study. J Viral Hepat 2009;16:94-103

37. van Zonneveld $M$, van Nunen $A B$, Niesters $H G$, de Man RA, Schalm SW, Janssen HL. Lamivudine treatment during pregnancy to prevent perinatal transmission of hepatitis B virus infection. J Viral Hepat 2003;10:294-297

38. van Nunen AB, de Man RA, Heijtink RA, Niesters HG, Schalm SW. Lamivudine in the last 4 weeks of pregnancy to prevent perinatal transmission in highly viremic chronic hepatitis B patients. J Hepatol 2000;32:1040-1041

39. Li XM, Yang YB, Hou HY, Shi ZJ, Shen HM, Teng BQ, et al. Interruption of HBV intrauterine transmission: a clinical study. World J Gastroenterol 2003;9:1501-1503

40. Su G-G, Pan H-K, Zhao N-F, Fang SH, Yang DH, Zhou Y. Efficacy and safety of lamivudine treatment for chronic hepatitis B in pregnancy. World J Gastroenterol 2004;10:910-912

41. Chotiyaputta W, Lok AS. Role of antiviral therapy in the prevention of perinatal transmission of hepatitis B virus infection (editorial). J Viral Hepat 2009;16:91-93

42. Chang MH. Decreasing incidence of hepatocellular carcinoma among children following universal hepatitis B immunization. Liver Int 2003;23:309-314

43. Hsu HY, Chang MH, Ni YH, Chen HL. Survey of hepatitis B surface variant infection in children 15 years after nation-wide vaccination program in Taiwan. Gut 2004;53:11499-11503

44. But DY, Lai CL, Lim WL, Fung J, Wong DK, Yuen MF. Twentytwo years follow-up of a prospective randomized trial of hepatitis $B$ vaccines without booster dose in children: final report. Vaccine 2008;26:6587-6591 
45. UNICEF. The State of the World's Children 2008 Child Survival [updated December 2007; cited 2009 May 11]. Available from: http://www.unicef.org/sowc08/docs/sowc08.pdf

46. Chongsrisawat V, Yoocharoen P, Theamboonlers A, Tharmaphornpilas P, Warinsathien P, Sinlaparatsamee S, et al. Hepatitis B seroprevalence in Thailand: 12 years after hepatitis $B$ vaccine integration into the national expanded programme on immunization. Trop Med Int Health 2006;11:1496-1502

47. Chen CJ, Yang HI, Su J, Jen CL, You SL, Lu SN, et al. Risk of hepatocellular carcinoma across a biological gradient of serum hepatitis B virus DNA level. JAMA 2006;295:65-73

48. Iloeje UH, Yang HI, Su J, Jen CL, You SL, Chen CJ. Predicting cirrhosis risk based on the level of circulating hepatitis B viral load. Gastroenterology 2006;130:678-686

49. Nguyen VT, Law MG, Dore GJ. An enormous hepatitis B virusrelated liver disease burden projected in Vietnam by 2025. Liver Int 2008;28:525-531
50. Koblin BA, Xu G, Lucy D, Robertson V, Bonner S, Hoover DR, et al. Hepatitis B infection and vaccination among high-risk noninjection drug-using women: baseline data from the UNITY study. Sex Transm Dis 2007;34:917-922

51. Lin SY, Chang ET, So SK. Why we should routinely screen Asian American adults for hepatitis B: a cross-sectional study of Asians in California. Hepatology 2007;46:1034-1040

52. Taylor VM, Choe JH, Yasui Y, Li L, Burke N, Jackson JC. Hepatitis $\mathrm{B}$ awareness, testing, and knowledge among Vietnamese American men and omen. J Community Health 2005;30:477-490

53. Weinbaum CM, Williams I, Mast EE, Wang SA, Finelli L, Wasley A, et al. Recommendations for identification and public health management of persons with chronic hepatitis B virus infection. MMWR Recomm Rep 2008;57:1-20

54. van der Eijk AA, de Man RA, Niesters HG, Schalm SW, Zaaijer HL. Hepatitis B virus (HBV) DNA levels and the management of HBV-infected health care workers. J Viral Hepat 2006;13:2-4 